\title{
A technique for the estimation of the effect of investments in the digitalisation of the dairy subcomplex entities
}

\author{
Mikhail Chernyakov ${ }^{1, *}$, Maria Chernyakova $^{2}$, Irina Chernyakova ${ }^{1,2}$, Kamal Akberov $^{3}$, Irina \\ Kharlamova $^{3}$, and Elena Sarycheva ${ }^{3}$ \\ ${ }^{1}$ Novosibirsk State Technical University, 630078, Karl Marx Ave.., 20, Novosibirsk, Russia \\ ${ }^{2}$ Siberian Institute of Management - Branch of Russian Academy of National Economy and State \\ Service Under the RF President, 630102, Nizhnegorskaya, 6, Novosibirsk, Russia \\ ${ }^{3}$ Novosibirsk State University of Economics and Management, 630099, 56 Kamenskaya str., \\ Novosibirsk, Russia
}

\begin{abstract}
The paper outlines the results of the analysis made to study the possibilities of using digital technologies to estimate the effect of investments in the digitalisation of dairy subcomplex entities. A review of academic literature revealed an insufficient number of publications on the dairy subcomplex digitalisation. The technique used to estimate the index of dairy subcomplex entities engaged the principles for constructing composite information indicators recommended by the European Commission. The proposed approach connects the system of state programmes and the digitalisation level of the dairy subcomplex for the first time. Taking into account the industry specifics, an attempt has been made to integrally estimate the digitalisation in dairy cattle breeding. It is recommended to introduce two criteria to assess the informational support level of dairy cattle breeding entities: the share and the index of dairy cattle breeding digitalisation. The correlation between the digitalization index of dairy cattle breeding and the return on equity has been established. An author's technique has been developed for a preliminary estimation of the effect of investments in digitalisation. The proposed approach develops the existing methods for estimating the effectiveness of government programs and policies, taking into account the industry digitalisation.
\end{abstract}

\section{Introduction}

The dairy industry develops under digitalisation influence along with the development of economic and mathematical theories, and their impact on the national economy by forming recommendations and suggestions in the field of public administration. Today, leading economists agree that state economic policy has been formed under the influence of developing economic and mathematical theories. However, there are disagreements concerning scales, mechanisms, and goals of such influence. Therefore, there is a problem

\footnotetext{
* Corresponding author: mkacadem@mail.ru
} 
of considering characteristics of forming main theoretical approaches to public administration problems, taking the dairy industry as an example [1].

Some milk and dairy producers are also involved in the digitalisation process. Producers of both milk and meat products use similar digital technologies. Digital technologies have already been partially implemented. In particular, extended sales analysis has been done in the field of big data analytics. Software interaction between pieces of equipment has been implemented in IoT. Besides, robot automation is implemented in some entities [2].

However, not all technologies are used; for example, machine learning and AI are not used. There are no ready-made solutions provided by major vendors, which could be easily put to work. It is rather expensive and time-consuming for milk and meat processing companies to develop from scratch.

There are risks in the implementation of digital technologies. The main one is a possible loss of time and money. There are no typical projects in the field of IoT or robot automation; it is always about search, research, in which researchers can go partway on the wrong track.

To increase the efficiency of digitalization of dairy subcomplex state regulation, the authors offer some recommendations:

- to introduce criteria for estimating the level of informational support of economic entities in the dairy subcomplex;

- to propose a method for estimating the effect of investments in digitalization.

According to the results of previous studies [3-9], it is required to introduce criteria for estimating the level of informational support of economic entities in the dairy subcomplex.

\section{Materials and Methods}

The method of assessing the index of dairy subcomplex entities has used the principles recommended by the European Commission for constructing composite information indicators given in the 2008 OECD / JRC Guidelines [10]. To justify the hypothesis, correlation and regression analysis methods are used.

The principles of constructing composite information indicators are used to develop digitalization indices of countries [11], business [12-14] (Fig. 1); in general, it can be expressed by the following formula:

$$
I_{d}=\left(I_{1}+I_{2}+\ldots+I_{i}+\ldots+I_{n}\right) / n,
$$

where $\mathrm{n}$ is a number of subindices included in the integral, measured in shares or per cent.

The Business Digitization Index (BDI), which is calculated by researchers from Otkrytie, Google, Mail.Ru Group, Skolkovo Moscow School of Management, RAEC and NAFI in accordance with five subindices: information transmission and storage channels, use of the Internet in sales, information security, digital learning [12]. Institute for Statistical Studies and Economics of Knowledge (ISSEK) of the Higher School of Economics has developed another analogue - the Business Digitalization Index [13] for an integral estimation of the digitalisation in the business sector [13]. It describes the rate of adaptation to digital transformation, the level of use of broadband Internet, cloud services, RFID technologies, ERP systems, and the involvement of business sector entities in ecommerce. The content of the "digitalisation index" term is shown in Fig. 1. 


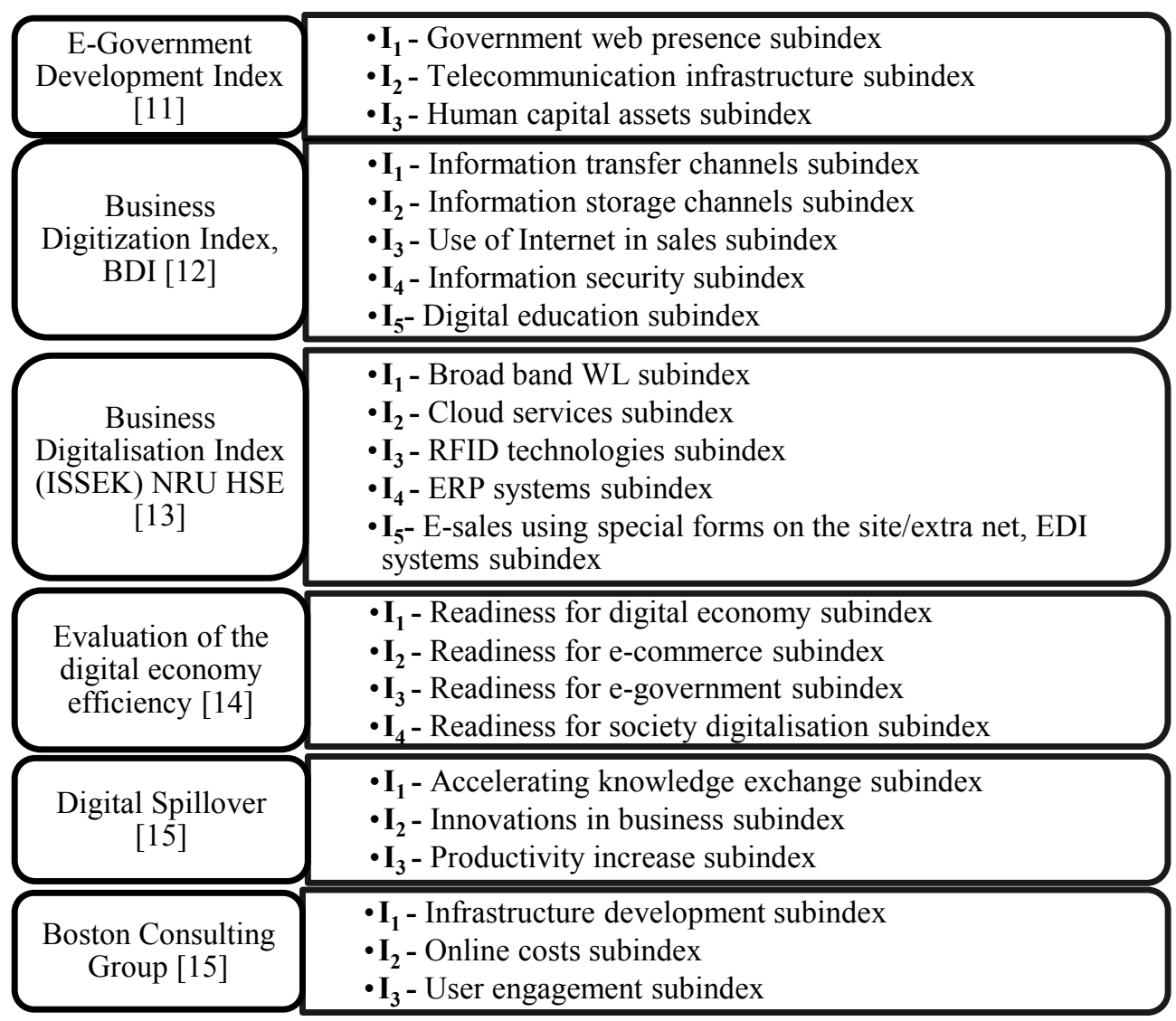

Fig. 1. Content of the "digitalisation index" term, [11-15]

\section{Results}

It is problematic to apply the indices (Fig. 1) to all economic entities of the dairy subcomplex since other digitalisation criteria are used in their estimation in cattle breeding and milk processing (Table 1). It should be noted that the characteristics listed in Table 1 can be applied in economic entities both comprehensively and partially; they can differ or coincide in terms of numbers.

Taking into account the industry specifics, an attempt has been made to integrally assess the level of digitalisation in dairy cattle breeding using two parameters: share $\left(\mathrm{I}_{\mathrm{s}-\mathrm{dcb}}\right)$ and digitalisation index $\left(\mathrm{I}_{\mathrm{d}_{\mathrm{d}} \mathrm{dcb}}\right)$. The first indicator characterizes the share of an economic entity among all entities involved in the digitalisation of the dairy herd, and the second one characterises four indicators (Table 1) of the rate of adaptation to digital transformation in terms of the level of use. Examples of calculating the proposed indicators of digitalization for the districts and economic entities of the Novosibirsk region (Table 1) are shown in Figures 2-5; they are performed according to expression (1) by the formula:

$$
I_{d \_d c b}=\left(I_{1}+I_{2}+I_{3}+I_{4}\right) / 4
$$


Table 1. Characteristics of precision livestock farming in the Maslyanino district of the Novosibirsk region, heads.

\begin{tabular}{|c|c|c|c|c|}
\hline Entity & $\begin{array}{c}\text { Livestock } \\
\text { product } \\
\text { quality } \\
\text { monitoring } \\
\left(I_{1}\right) \\
\end{array}$ & $\begin{array}{c}\text { Electronic } \\
\text { production } \\
\text { process } \\
\text { database }\left(I_{2}\right)\end{array}$ & $\begin{array}{c}\text { Identification } \\
\text { and } \\
\text { monitoring of } \\
\text { individual } \\
\text { animals }\left(\mathrm{I}_{3}\right) \\
\end{array}$ & $\begin{array}{c}\text { Herd } \\
\text { health } \\
\text { monitorin } \\
\text { g }\left(\mathbf{I}_{4}\right)\end{array}$ \\
\hline Sibirskaya Niva LLC & 8391 & 18699 & 17025 & 17025 \\
\hline Sibirskiy Pakhar LLC & 423 & & & \\
\hline $\begin{array}{l}\text { Individual Entrepreneur A.I. } \\
\text { Gerasimov, Head of the farm }\end{array}$ & 160 & & & \\
\hline $\begin{array}{l}\text { Individual Entrepreneur } \\
\text { Gasymov Ch.R.O. }\end{array}$ & 20 & & & \\
\hline
\end{tabular}

The data shown in Figure 2 show a low rate of adaptation to the digital transformation of the dairy industry in the Novosibirsk region. Only 12 of 29 districts of the Novosibirsk region are being digitalised, which is less than half. The index shown in Figure 1 shows that $15.6 \%$ of the Novosibirsk region's dairy herds have been digitised in general. Moreover, the Maslyanino district is the leader (digitalisation index $=82.5 \%$ ), and the Tatarsk district is the outsider (digitalisation index $=<1 \%$ ). The wide scatter of the obtained index values $(82 \%)$ is indicative of a significant differentiation in the digitalization level even in the districts where it is being performed.

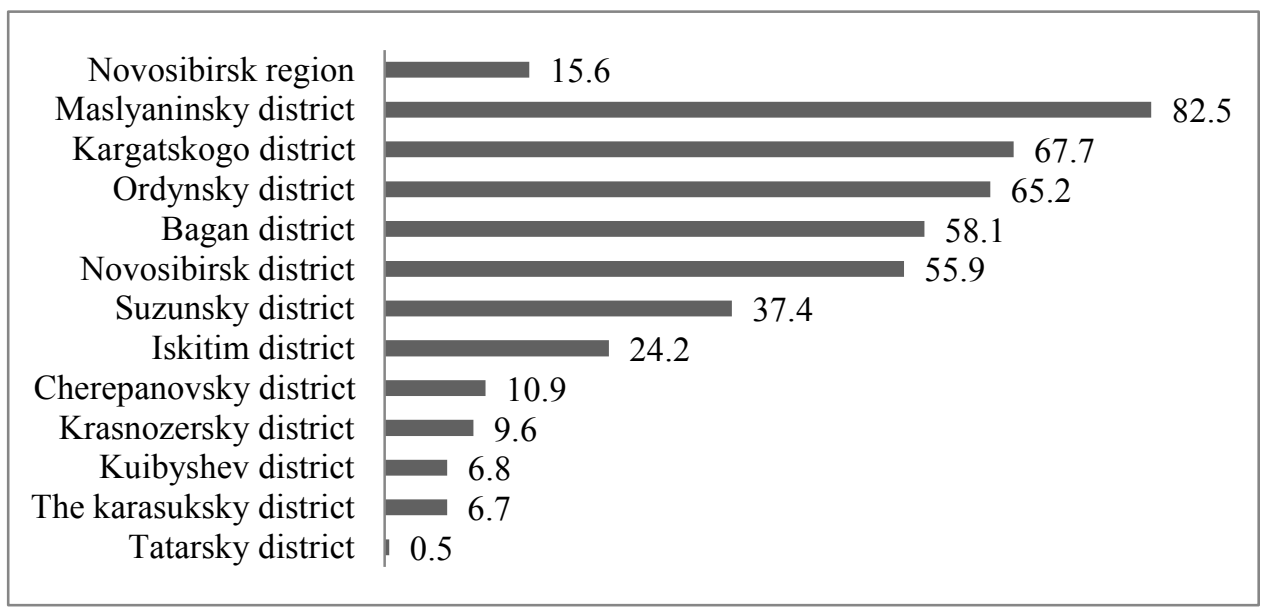

Fig. 2. Digitalisation index of dairy cattle breeding in districts of the Novosibirsk region

The digitalisation index of dairy cattle breeding in economic entities is calculated in the same way (Fig. 3). Figure 3 shows the top- 10 of leaders with more than $70 \%$ of the digitalised dairy herd. The second indicator of the integral estimation, which describes the share of the economic entity among all subjects involved in the digitalisation of the dairy herd is shown in Fig. 4-5. 


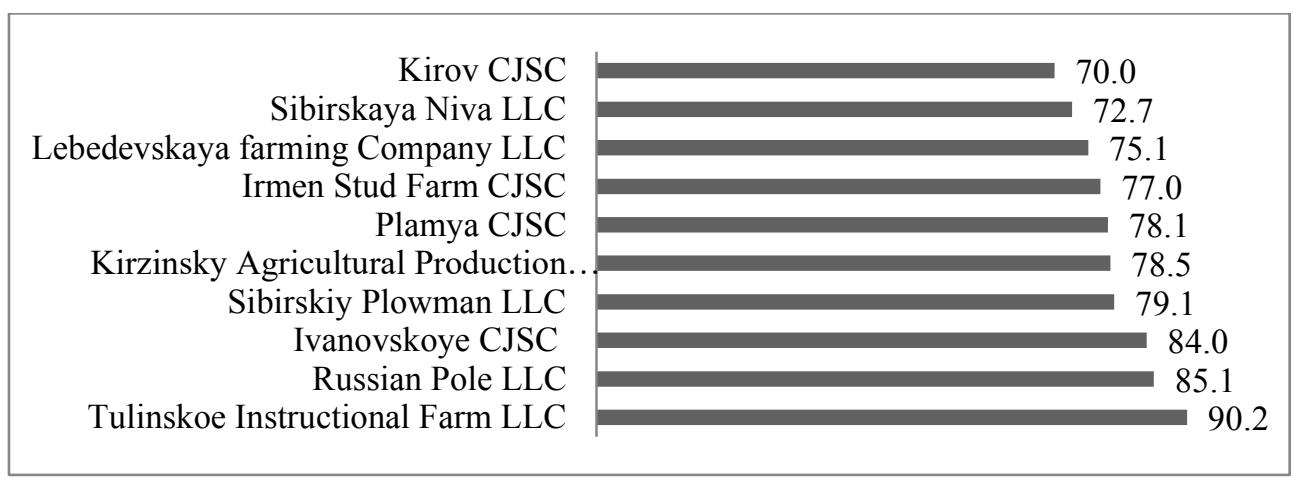

Fig. 3. Digitalisation index of dairy cattle breeding in entities of the Novosibirsk region

Data shown in Figure 4 confirm the conclusions obtained earlier. According to the digitalisation share, top-3 of the leaders includes the same districts of the Novosibirsk region as for the digitalisation index: the Maslyanino, Kargat, and Ordynskoe districts. The digitalisation share in these districts is more than $65 \%$. As shown in Figure, only five of twelve districts of the region have more than half of the dairy cattle breeding digitalised. In the other seven districts, the digitalisation share is even lower than $40 \%$, and this share is lower than $10 \%$ in four of these seven districts. It shows that the districts are not ready for the digital transformation.

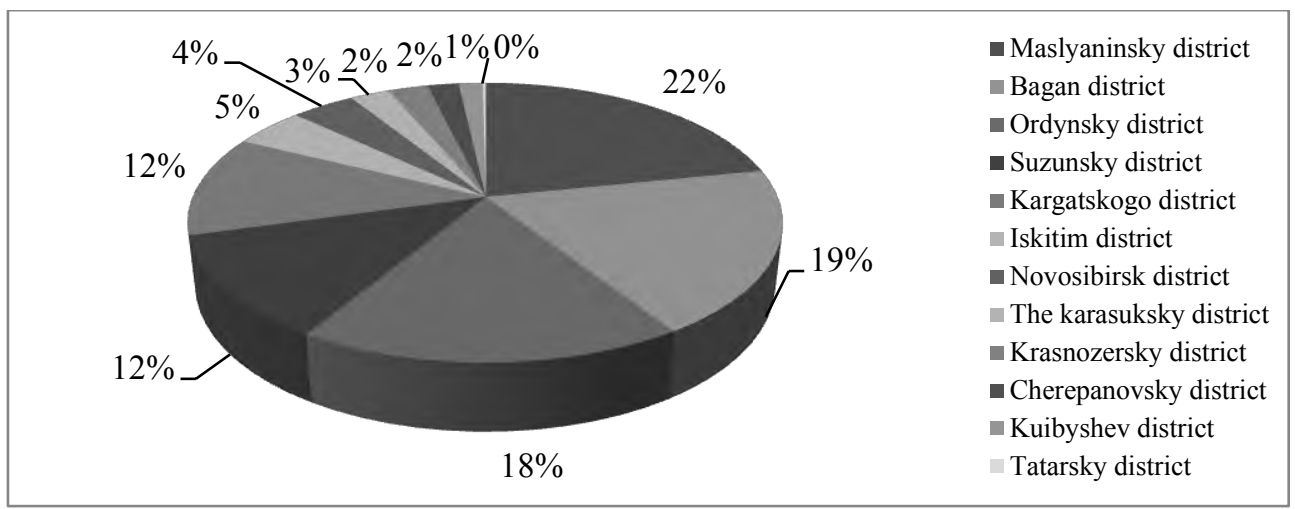

Fig. 4. Digitalisation share of dairy cattle breeding in the districts of the Novosibirsk region

Twenty-nine economic entities (Fig. 5) including two individual entrepreneurs are digitalising the dairy cattle breeding in 12 districts of the Novosibirsk region. Moreover, Top-3 makes almost half of the share in the field of dairy cattle breeding digitalisation.

Of special interest is the possibility to make a connection between financial parameters and digitalisation index proposed by authors. Comparative characteristics of financial indicators of three economic entities of the Novosibirsk region with digitalisation parameters are shown in Table 2, and the correlation analysis 10 (Fig. 3) is shown in Table 3 . The correlation analysis has shown that financial indicators (except for net profit, equity and profitability) have a strong correlation (correlation ration $\mathrm{R}>0.7$ ) with the digitalisation share, especially the "current assets" parameter $(\mathrm{R}=0.98)$. The digitalisation index of dairy cattle breeding has shown a close correlation only with ROE $(r=0.77)$ and the absence of correlation even with the digitalisation share $(\mathrm{R}=-0.29)$, which indicates that the proposed digitalisation parameters do not duplicate, but complement each other. It should also be noted that the correlation of digitalisation index of dairy cattle breeding with ROE components (net profit $(\mathrm{R}=-0.13)$ and equity $(\mathrm{R}=-0.19))$ is also absent. 


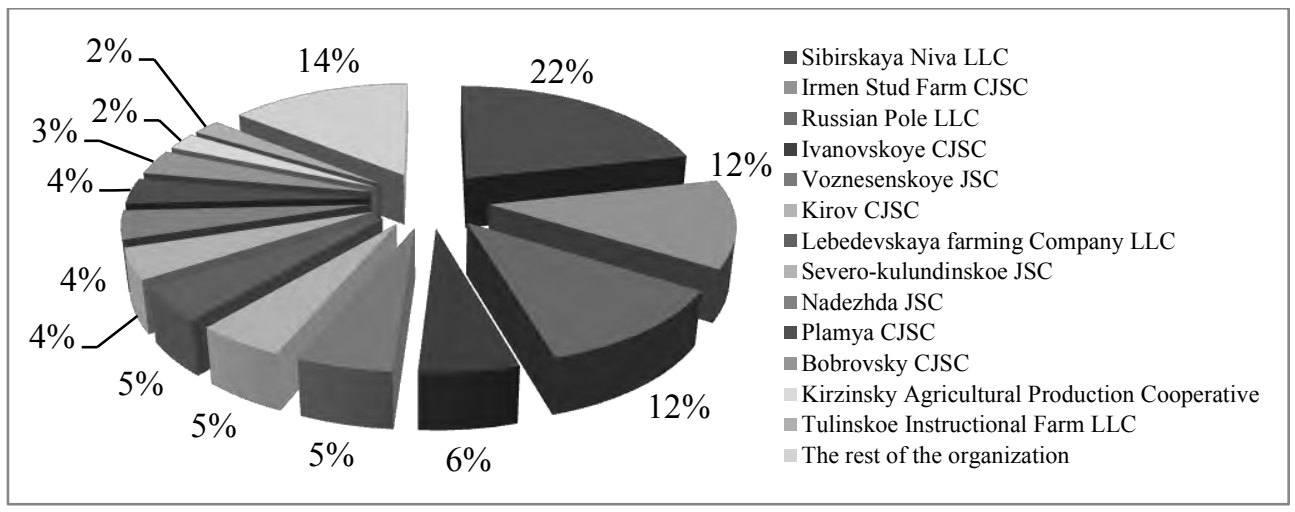

Fig. 5. Share in dairy cattle breeding digitalisation of economic entities in the Novosibirsk region

Table 2. Comparative characteristics of financial indicators of 3 economic entities of the Novosibirsk region with digitalization parameters*

\begin{tabular}{|c|l|c|c|c|}
\hline \multicolumn{1}{|c|}{ Indicator } & $\begin{array}{c}\text { Irmen stud } \\
\text { farm CJSC }\end{array}$ & $\begin{array}{c}\text { Sibirskaya Niva LLC } \\
\text { (EcoNiva-APK Holding } \\
\text { Group) }\end{array}$ & $\begin{array}{c}\text { Russkoe pole } \\
\text { farm LLC }\end{array}$ \\
\hline Y1 & Revenue & 2495091 & 2023843 & 1463589 \\
\hline Y2 & Cost of sales & 2071171 & 1732180 & 1353470 \\
\hline Y3 & Profit on sales & 406496 & 289214 & -1969 \\
\hline Y4 & Net profit & 486133 & 62982 & 26975 \\
\hline Y5 & Equity & 3286493 & 445131 & 43654.5 \\
\hline Y6 & Capital assets & 1754369 & 6214146.5 & 5531414.5 \\
\hline Y7 & Current assets & 1716231 & 3882333 & 2021256 \\
\hline Y8 & The total value of assets & 3470600 & 10096479.5 & 7552670.5 \\
\hline Y9 & Return on sales by net profit & 19.48 & 3.11 & 1.84 \\
\hline Y10 & Return on equity & 14.79 & 14.15 & 61.79 \\
\hline Y11 & Return on assets & 14.01 & 0.62 & 0.36 \\
\hline Y12 & Digitalisation, \% & 12.252 & 21.556 & 11.708 \\
\hline Y13 & Digitalisation volume & 34752 & 61140 & 33208 \\
\hline Y14 & $\begin{array}{l}\text { Digitalisation index of dairy } \\
\text { cattle breeding, \% }\end{array}$ & 77.0 & 72.7 & 85.1 \\
\hline & & & & \\
\hline
\end{tabular}

The correlation of the digitalisation index of dairy cattle breeding with ROE, with a relative error $>10 \%$, which is less than the allowed $15 \%$, may be represented as the following regression equation:

$$
Y_{14}=0.17 * Y_{10}+74.258 \text { or } I_{d \_d c b}=0.17 * R O E+74.258 .
$$

Table 3. Correlation analysis of comparative financial indicators of 3 economic entities of the Novosibirsk region with digitalization parameters* 


\begin{tabular}{|c|c|c|c|c|c|c|c|c|c|c|c|c|c|c|}
\hline & $\mathrm{Y} 1$ & $\mathrm{Y} 2$ & $\mathrm{Y} 3$ & $\mathrm{Y} 4$ & $\mathrm{Y} 5$ & $\mathrm{Y} 6$ & $\mathrm{Y} 7$ & $\mathrm{Y} 8$ & $\mathrm{Y} 9$ & $\mathrm{Y} 10$ & $\mathrm{Y} 11$ & $\mathrm{Y} 12$ & $\mathrm{Y} 13$ & $\mathrm{Y} 14$ \\
\hline Y1 & 1.00 & 1.00 & 0.88 & 0.73 & 0.69 & 0.74 & 0.85 & 0.79 & 0.14 & 0.05 & 0.25 & 0.87 & 0.87 & 0.23 \\
\hline Y2 & 1.00 & 1.00 & 0.85 & 0.70 & 0.66 & 0.77 & 0.86 & 0.81 & 0.18 & 0.05 & 0.28 & 0.88 & 0.88 & 0.23 \\
\hline Y3 & 0.88 & 0.85 & 1.00 & 0.84 & 0.83 & 0.44 & 0.69 & 0.53 & 0.19 & 0.15 & 0.01 & 0.73 & 0.73 & 0.31 \\
\hline Y4 & 0.73 & 0.70 & 0.84 & 1.00 & 0.99 & 0.10 & 0.31 & 0.18 & 0.44 & 0.10 & 0.14 & 0.38 & 0.38 & 0.13 \\
\hline Y5 & 0.69 & 0.66 & 0.83 & 0.99 & 1.00 & 0.05 & 0.26 & 0.12 & 0.43 & 0.20 & 0.09 & 0.35 & 0.35 & 0.19 \\
\hline Y6 & 0.74 & 0.77 & 0.44 & 0.10 & 0.05 & 1.00 & 0.94 & 0.99 & 0.52 & 0.12 & 0.44 & 0.89 & 0.89 & 0.10 \\
\hline Y7 & 0.85 & 0.86 & 0.69 & 0.31 & 0.26 & 0.94 & 1.00 & 0.97 & 0.38 & 0.01 & 0.38 & $\mathbf{0 . 9 8}$ & $\mathbf{0 . 9 8}$ & 0.26 \\
\hline Y8 & 0.79 & 0.81 & 0.53 & 0.18 & 0.12 & 0.99 & 0.97 & 1.00 & 0.48 & 0.07 & 0.42 & 0.94 & 0.94 & 0.16 \\
\hline Y9 & 0.14 & 0.18 & 0.19 & 0.44 & 0.43 & 0.52 & 0.38 & 0.48 & 1.00 & 0.06 & 0.60 & 0.37 & 0.37 & 0.22 \\
\hline Y10 & 0.05 & 0.05 & 0.15 & 0.10 & 0.20 & 0.12 & -0.01 & 0.07 & 0.06 & 1.00 & 0.72 & 0.05 & 0.05 & $\mathbf{0 . 7 7}$ \\
\hline Y11 & 0.25 & 0.28 & 0.01 & 0.14 & 0.09 & 0.44 & 0.38 & 0.42 & 0.60 & 0.72 & 1.00 & 0.38 & 0.38 & 0.58 \\
\hline Y12 & 0.87 & 0.88 & 0.73 & 0.38 & 0.35 & 0.89 & $\mathbf{0 . 9 8}$ & 0.94 & 0.37 & 0.05 & 0.38 & 1.00 & 1.00 & 0.29 \\
\hline Y13 & 0.87 & 0.88 & 0.73 & 0.38 & 0.35 & 0.89 & $\mathbf{0 . 9 8}$ & 0.94 & 0.37 & 0.05 & 0.38 & 1.00 & 1.00 & 0.29 \\
\hline Y14 & 0.23 & 0.23 & 0.31 & 0.13 & 0.19 & 0.10 & 0.26 & 0.16 & 0.22 & $\mathbf{0 . 7 7}$ & 0.58 & 0.29 & 0.29 & 1.00 \\
\hline
\end{tabular}

The mathematical model analysis (3) shows that the average digitalization index of dairy cattle breeding in business entities of the Novosibirsk region, which perform the chipisation of dairy herds, is $74 \%$; its deviations with a ratio of 0.17 depend on the ROE. Hence, the entities which plan to chipise their dairy herds can predict a rational digitalisation index of dairy cattle breeding.

The authors of digital spillover [14] have empirically proved that investments in digital assets are significantly more profitable than in non-digital ones. Every US dollar invested in digital technologies over the past three decades has generated an average of USD 20 to GDP. This is a huge return compared to non-digital investments, which generate an average income of between USD 3 to USD 1. The investment of USD 1 is 6.7 times more profitable for digital investments than for non-digital ones. Therefore, the investment efficiency ratio $\left(\mathrm{K}_{\mathrm{e}}\right)$ based on empirical data can be equal to 6.7 for the digitalisation index $\mathrm{I}_{\mathrm{d}}=1(100 \%)$. The expected economic effect $\left(\mathrm{E}_{\mathrm{x}}\right)$ of investments $\left(\mathrm{X}_{\mathrm{i}}\right)$ in digitalisation, taking into account the digitalisation index, can be calculated using the formula:

$$
E_{x}=X_{i} \cdot I_{d} \cdot K_{e} .
$$

\section{Discussion}

Twenty-nine economic entities (Fig. 5) including two individual entrepreneurs are digitalising the dairy cattle breeding in 12 districts of the Novosibirsk region. Moreover, Top-3 makes almost half of the share in the field of dairy cattle breeding digitalisation.

Of special interest is the possibility to make a connection between financial parameters and digitalisation index proposed by authors. Comparative characteristics of financial indicators of three economic entities of the Novosibirsk region with digitalisation parameters are shown in Table 2, and the correlation analysis 10 (Fig. 3) is shown in Table 3. The correlation analysis has shown that financial indicators (except for net profit, equity and profitability) have a strong correlation (correlation ration $\mathrm{R}>0.7$ ) with the digitalisation share, especially the "current assets" parameter $(\mathrm{R}=0.98)$. The digitalisation index of dairy cattle breeding has shown a close correlation only with ROE $(r=0.77)$ and the absence of correlation even with the digitalisation share $(\mathrm{R}=-0.29)$, which indicates 
that the proposed digitalisation parameters do not duplicate, but complement each other. It should also be noted that the correlation of digitalisation index of dairy cattle breeding with ROE components (net profit $(R=-0.13)$ and equity $(R=-0.19))$ is also absent.

\section{Conclusions}

It is recommended to introduce two criteria to assess the informational support level of dairy cattle breeding entities: the share and the dairy cattle breeding digitalisation index. The first indicator describes the share of the economic entity among all entities, which participate in the digitalisation, and the second one describes the rate of adaptation to the digital transformation by the level of use of precision livestock farming characteristics.

The study results indicate the presence of general patterns and correlation between the elements of digital technologies provided by government programmes and the efficiency of the dairy industry entity functioning. The analysis allows us to assert that digital technologies, which are elements of state regulation of the dairy industry introduced into the activities of corporations, have a significant impact on business efficiency.

This indicates a possibility of managing the digitalisation with the given parameters of business performance and a possibility to predict the key indicator: the digitalisation index based on the constructed regression equation.

The authors propose a formula based on empirical data from the preliminary estimations of the expected economic effect of investments in digitalisation, which shows that the most excellent effect can be achieved with full (100\%) digitalisation. Partial digitalisation will not have the desired effect and may even be unprofitable under certain conditions. Therefore, it is recommended to digitalise business entities comprehensively. In case of a lack of funds, they should be digitalised pointwise, without spreading the financial asset over many entities.

The reported study is funded by RFBR according to the research project № 20-310-90002.

\section{References}

1. M. Chernyakov, M. Chernyakova, Modelling of the process of regulating production, processing and marketing of milk and milk products, IOP Conference Series: Materials Science and Engineering, 656(1), 012014 (2019) doi: 10.1088/1757899X/656/1/012014.

2. M. S. Oborin, Digitalization of business processes in the field of food services as a factor in improving the food security of the region, 1st International Scientific Conference "Modern Management Trends and the Digital Economy: from Regional Development to Global Economic Growth" (MTDE 2019), Advances in Economics, Business and Management Research, 81, 83-99 (2019) doi: 10.2991/mtde-19.2019.69.

3. A. Pimenova, S. Kuzmina, V. Vaganova, E. Yahvarov, Digitalization tools in ensuring the efficiency of the enterprise activity, ACM International Conference Proceeding Series, 32, 1-4 (2020) https://doi.org/10.1145/3388984.3390641

4. N. P. Karachyna, M. O. Samofalova, Y. V. Bilyak, N. I. Drahnieva, An analysis of variability and mutual coordination of models of the economic behaviour of enterprises in digital space, International Journal of Advanced Science and Technology, 29(6), 1057-1065 (2020)

5. Y. Zaitsev, O. Ponomariov, and et., Analysis of the Modern Monitoring Implementation Methods as the Main Stage of Digitalization of the Agrarian 
Enterprises, International Journal of Advanced Science and Technology, 29(6), 10141021 (2020)

6. N. Sirotkina, E. Shkarupeta, V. Kruglyakova, A. Batova, Digital risk management, E3S Web of Conferences, 164, $10055 \quad$ (2020) doi: https://doi.org/10.1051/e3sconf/202016410055

7. A. Gladkova, M. Ragnedda, Exploring digital inequalities in Russia: an interregional comparative analysis, Online Information Review, 44(4), 767-786 (2020)

8. M. Pech, J. Vrchota, Classification of Small- and Medium-Sized Enterprises Based on the Level of Industry 4.0 Implementation, Applied Sciences (Switzerland), 10(15), 5150 (2020) https://doi.org/10.3390/app10155150

9. O. Trubetskaya, Features of Digitalization of the Business Sector in the Russian Economy, Current Achievements, Challenges and Digital Chances of KnowledgeBased Economy, 1, 315-320 (2021) doi: 10.1007/978-3-030-47458-4_37

10. European Commission: EU Science Hub. The European Commission's science and knowledge service (2008) URL: https://ec.europa.eu/jrc/en/coin/10-stepguide/overview (Last accessed 12.06.2020)

11. A. Whitmore, A statistical analysis of the construction of the United Nations EGovernment Development Index, Government Information Quarterly, 29(1), 68-75 (2012) doi: 10.1016/j.giq.2011.06.003.

12. M. Chernyakov, M. Chernyakova, I. Chernyakova, G. Gritsenko, Identification of regions in need of crisis management using the example of the dairy industry. E3S Web of Conferences, 175, 13024 (2020) DOI: 10.1051/e3sconf/202017513024.

13. M. Chernyakov, M. Chernyakova, I. Chernyakova, Inno-diversification approach to regulating the dairy industry transformation into the digital economy, Advances in Economics, Business and Management Research, 131, 16-23 (2020) DOI: 10.2991/aebmr.k.200324.004.

14. Digital Spillover: Measuring the true impact of the digital economy (2017) URL: https://www.huawei.com/minisite/gci/en/digitalspillover/files/gci digital spillover.pdf (Last accessed 12.06.2020)

15. M. Chernyakov, M. Chernyakova, K. Akberov, Innodiversification model of the digital economy of the agricultural sector. Advances in Social Science, Education and Humanities Research, 240, 262-267 (2019) doi: 10.2991/sicni-18.2019.114. 